\begin{tabular}{|l|l|l|}
\hline & ESCOLA DE \\
PUCRS & HUMANIDADES & $\begin{array}{l}\text { Conversas \& Controvérsias, Porto Alegre, v. 7, n. 1, p. 1-4, jan.-jun. } 2020 \\
\text { e-ISSN: 2178-5694 }\end{array}$ \\
\hline Inttp://dx.doi.org/10.15448/2178-5694.2020.1.35813 & \\
\hline
\end{tabular}

SEÇÃO: RESENHA

\title{
O que é encarceramento em massa? de Juliana Borges
}

\author{
What is mass incarceration? from Juliana Borges
}

\section{Maciana de Freitas e \\ Souza ${ }^{1}$ \\ orcid.org/0000-0003-2291-0411 \\ macianafreitas@hotmail.com}

\section{Francisca Ilania de}

Alencar ${ }^{1}$

orcid.org/0000-0002-0926-9853

ilania_alencar@hotmail.com

Publicado em: 17 set. 2020
Resumo: A presente resenha tem como propósito apresentar a obra da pesquisadora Juliana Borges intitulada O que é encarceramento em massa? Adotando uma perspectiva crítica, a autora busca promover uma reflexão sobre o controle social e a violência estatal destinada à população negra, apontando que as relações sociais e o quadro jurídico-institucional em curso na realidade brasileira acentuam os elementos que sustentam as desigualdades.

Palavras-chaves: Encarceramento em massa. População negra. Controle social.

Abstract: The purpose of this review is to present the work of researcher Juliana Borges entitled "what is mass incarceration"? Adopting a critical perspective, the author seeks to promote a reflection on social control and state violence aimed at the black population, pointing out that the social relations and the legal-institutional framework underway in the Brazilian reality accentuate the elements that support inequalities. Keywords: Mass incarceration. Black population. Social control.

BORGES, Juliana. 2018. O que é: encarceramento em massa? Belo Horizonte: Letramento.

O livro O que é encarceramento em massa? escrito pela pesquisadora e ativista Juliana Borges, faz parte da série Feminismos Plurais, tem como objetivo introduzir questões relativas ao sistema criminal e o seletismo penal ao elencar suas consequências negativas principalmente à população jovem e negra. A obra de Juliana Borges se inicia com a exposição das origens do sistema escravocrata e os seus efeitos na realidade brasileira. Segundo Borges, "abolida a escravidão no país, como prática legalizada de hierarquização racial e social, outros foram os mecanismos e aparatos que se constituíram e se reorganizaram [...] como forma de garantir controle social" (Borges 2018, 37).

Para a autora, a taxa de negros comparada à taxa de brancos aprisionados tem crescido constantemente nas últimas décadas. No Brasil, diversos fatores podem ter influenciado diretamente neste processo tendo como base a ampliação das políticas neoliberais, o aumento do controle punitivo sobre a juventude negra, bem como a ênfase na guerra às drogas pelo Estado. Nesse sentido, são diversos os mecanismos que contribuem nas situações de segregação dos sujeitos. Por isso, precisamos refletir sobre o papel estatal e as interfaces que são produzidas no campo das práticas de segurança pública. Nas palavras de Borges: 
O sistema de justiça criminal tem profunda comais do que perpassados por esta estrutura de opressão, mas o aparato reordenado para garantir a manutenção do racismo e, portanto, das desigualdades baseadas na hierarquizaencarcerado significa a negação de uma série encarcerado significa a negação de uma série
de direitos e uma situação de aprofundamento de vulnerabilidades. (Borges 2018, 16)

Em uma leitura critica, Borges pontua que é necessário avançar na análise sobre a manutenção do controle social e da função de segregação que as prisões promovem. Dialogando com Alexander sobre o sistema de justiça, afirma que "Não se trata da prevenção e punição do crime, mas sim da gestão e do controle dos despossuidos" (Alexander 2018, 9). A partir desses entendimentos, Segundo Borges, têm sido recorrentes, medidas que legitimam a violência estatal, e o perfil da população selecionada pelo sistema prisional brasileiro é bem especifico. " $56 \%$ dos acusados em varas criminais são negros, enquanto em juizados especiais que analisam casos menos graves, este número inverte tendo maioria branca (52,6\%)" (Borges 2018, 83). Borges ressalta que, a partir do neoliberalismo, além do desmonte das políticas sociais, podemos notar que diante de tal contexto se apresentam respostas repressivas por parte dos poderes constituidos. Segundo Borges, "Nosso pensamento é condicionado a pensar as prisões como algo inevitável para quaisquer transgressões convencionadas socialmente. Ou seja, a punição já foi naturalizada no imaginário social" (Borges 2018, 30). Com base nessa realidade questiona "as prisões estão sendo espaços de real ressocialização como se propõe?" (Borges 2018, 30). Para a autora, nessa ótica, as políticas de segurança repressivas são reforçadas na dinâmica social, dificultando ainda mais os processos de organização e resistência da juventude negra aos niveis de expropriação dos direitos. Tal processo repercute na existência de espaços de exceção e da inscrição da seletividade do sistema penal. Dando continuidade ao debate, a autora pontua que o crescimento massivo de presos não é uma medida suficientemente eficaz para conter a violência. Como resultado, podemos notar a questão da superlotação, bem como violações de direitos, elementos que favorecem a questão da reincidência. Nesse processo, destaca-se também o papel coercitivo estatal, com políticas de controle punitivo na contramão de um processo penal democrático, na qual as garantias processuais são deixadas em segundo plano Assim, o racismo tem um grande efeito no índice de encarceramento e o Estado, no que se refere à juventude negra, tem atuado para a produção de iniciativas voltadas à punição

Utilizam-se técnicas e desenvolvem-se aparatos meticulosamente planejados para a execução Ou seja, não há, nessa lógica sistêmica a intencionalidade de controle de determinados grupos sociais. O processo de exploração e do ciclo em que se estabelecem as relações neoliberais opera pelo exterminio dos grupos que não têm da exclusão para o exterminio. (Borges 2018, 23)

Ao longo do texto, Borges questiona o autoritarismo presente no Brasil contemporâneo, ressalta que o racismo é uma prática institucionalizada, e que devido a isso, "a guerra às drogas é central no genocidio da população negra brasileira" (Borges 2018, 105). Nesse sentido, a autora acrescenta que na realidade brasileira, é muito importante perceber que em termos de direitos, o Estado tem atuado com respostas conservadoras no enfrentamento às expressões da violência, ampliando ainda mais as desigualdades sociais. Borges considera que:

Esta situação de ambiguidade em relação à escravidao demonstra o Direito e Justiça priminal sendo constitutivos do escravismo e, da criminalização e extermínio da população negra e não um mero aparato perpassado pela ideologia racista. (Borges 2018, 71)

Desse modo, entende-se que violência está ligada à estrutura social e reproduz-se no cotidiano dos diversos grupos, e tem se mostrado cada vez mais presente no cotidiano da juventude negra. Nessa perspectiva, as politicas de segurança pública na conjuntura brasileira são criadas para servir aos interesses neoliberais e têm operado para a manutenção do racismo de Estado. Em vista disso, a organização politica e econômica da sociedade coopera com a manutenção do racismo no tecido social, assim, podemos notar um aumento das violências diversas praticadas contra a juventude negra e periférica, o que reforça a ideia de que as tarefas democráticas não estão sendo conduzidas pelo Estado. No que se refere ao encarceramento feminino acrescenta:

No Brasil, apenas a partir dos anos 80 que bridade e ambientes próprios para as mulheres em situação prisional. Mas é mais pós anos 90 que se inicia um movimento de reforma de separação, mas com igualdade. Ocorre que a dupla e tripla condição de opressão da maioria esmagadora das mulheres que compõe o sistema prisional. (Borges 2018, 95 )

Em virtude do aumento do encarceramento feminino, Borges ressalta a importância de pensar a categoria gênero nas discussões sobre o sistema de justiça e segurança. Para a autora, "na grande parte dos estudos e ativismo em torno da pauta do sistema criminal, pouca é a atenção dada ao debate de gênero" (Borges 2018, 89). Destarte, nesse contexto de controle estatal da criminalidade "As mulheres, por sua vez, são o segmento que mais tem sentido estes impactos" (Borges 2018, 98). Nesses termos, é preciso reconhecer o controle social em curso, para reafirmar nossa luta por uma sociedade justa, na qual o Estado brasileiro possa atuar no sentido de eliminar formas de violência e discriminação promovendo o direito à plena inclusão e participação social dos grupos minoritários. Desse modo, podemos entender que o aumento do encarceramento feminino no Brasil revela as desigualdades de gênero e as violências institucionais por parte do Estado, nas quais elencam respostas punitivas demandadas por diversos setores da sociedade, a exemplo dos meios de comunicação, os grupos políticos e as parcelas da população que são a favor de ações que legitimam a privação de liberdade, bem como questionam o contexto em que os direitos humanos se inserem. Para a autora, as respostas e o entendimento acerca da responsabilização podem se dar em outros termos, que não os restritos a um modelo penal. Esse outro caminho é pela formulação de políticas públicas afirmadoras de cidadania e intervenções normativas com vistas a ampliação das liberdades públicas e os direitos fundamentais.

Assim, nesse contexto, Borges (2018) apresenta a ideia que o sistema criminal busca neutralizar, sobretudo, as pessoas de minorias étnicas e de grupos sociais e economicamente mais vulneráveis. Dessa maneira, o racismo não só dificulta o acesso aos direitos para a juventude negra, como também fomenta o aumento do encarceramento feminino no Brasil. tendo como alvo principalmente mulheres negras e pobres. A interlocução entre as referências levantadas nos levam a concluir que o Estado brasileiro está a serviço dos interesses do poder dominante, mantendo uma democracia restrita e uma série de acontecimentos que fortalece a violência estatal.

Portanto, o livro é relevante para compreendermos a expansão prisional no Brasil e que "precisamos repensar o sistema de justiça para que se organize não pela vingança e punição, mas principalmente, pela restauração e reconciliação' (Borges 2018, 118). No mais, esse cenário demonstra que a violência enquanto expressão da questão social deve ser enfrentada por meio de políticas sociais em diversas áreas, o caminho não é ampliar os mecanismos de punição. Trata-se portanto, de uma reflexão teórica necessária para entendermos as ações realizadas pelo sistema de justiça criminal, e ademais reforça a importância da criação de políticas de segurança que sejam efetivas e consigam reduzir os indices de violência, tendo como base o texto constitucional de 1988 e os direitos humanos estabelecidos.

\section{Referências}

Alexander, Michelle. 2018. A nova segregação: racismo e encarceramento em massa. São Paulo: Boitempo. Borges, Juliana. 2018. O que é encarceramento em
massa? Belo Horizonte Letramento.

\section{Maciana de Freitas e Souza}

sidade do Estado do Rio Grande do Norte (UERN), em Mossoró, RN Brasil. Pos-graduada em Saúde Publica com Enfase en Saúde da Familia pela Faculdade Vale do Jaguaribe de rua com foco na população negra Universidade de Brasilia (UnB), em Brasilia, DF, Brasil. 


\section{Francisca Ilania de Alencar}

Licenciada em Ciências Sociais pela Universidade do Estado do Rio Grande do Norte (UERN), em Mossoró, $\mathrm{RN}$, Brasil. 